\title{
Wilfried Floeck, Estudios críticos sobre el teatro español, mexicano y portugués contemporáneo, edición de Herbert Fritz, Ana García Martínez y Sabine Fritz, Hildesheim, Georg Olms Verlag, 2008, 257 pp.
}

La colección dedicada a la Teoría y Práctica del Teatro de la editorial Georg Olms ofrece este volumen en el que se reúnen algunos de los más importantes y recientes trabajos del profesor Wilfried Floeck. H. Fritz, A. García Martínez y S. Fritz, con motivo de la jubilación del hispanista, vuelven a la fórmula que ya llevaran a cabo en su sesenta aniversario, entonces con otro nutrido grupo de estudios sobre teatro español del siglo XX que cosechó un gran éxito entre los estudiosos de ámbito internacional. Como los editores subrayan en la introducción al volumen, los ensayos en él presentados, que abarcan el ámbito del teatro español, mexicano y portugués, avalan la calidad y la excelencia científicas de este segundo volumen que presenta una amplia gama de diferentes enfoques en el tratamiento de temas literario-culturales que se reparten a lo largo del mismo.

En la estructura del libro se distinguen claramente tres líneas de investigación, la dedicada al teatro español de los siglos XX y XXI, que ocupa la primera y más extensa parte del volumen y a la que corresponden los nueve primeros capítulos a los que se une el décimo, dedicado al teatro actual en España y Portugal en el contexto de la postmodernidad, que actúa como puente de unión con el segundo bloque, más breve, que comprende dos capítulos dedicados exclusivamente al teatro portugués, para finalizar con un tercer grupo de dos capítulos dedicados al drama mexicano.

El trabajo que inaugura esta ilustradora antología está dedicado a las figuras de Pirandello, Unamuno y Jacinto Grau, la puesta en escena de sus dramas y las posibles relaciones entre los mismos. Analiza el autor la recepción de Pirandello en España, la influencia de algunas obras de este autor sobre Unamuno y el evidente, en palabras del crítico, pirandelismo de Grau en El señor de Pigmalión.

Del estudio de la recepción del autor italiano en España y de las conexiones de éste con la escena española se pasa a la reflexión sobre el teatro postfranquista y el papel de actor y director en la escena española, análisis que ocupa el segundo de los trabajos en el que se centra la atención en el diálogo director-autor a lo largo del siglo XX, partiendo del ámbito internacional para dar paso al análisis de la situación en España a lo largo del siglo pasado hasta la actualidad. El tercer estudio del libro se puede considerar continuación del anterior pues en él nuestro crítico reflexiona sobre el teatro español de finales del siglo XX y realiza un intento de definición del complejo y arriesgado concepto de postmodernidad y los planteamientos dramáticos en la línea del compromiso social que marca el perfil de una ética postmoderna que no 
“consiste únicamente en una mirada crítica sobre la cara oscura de la realidad social actual, sino que desarrolla, al mismo tiempo, nuevos valores positivos deducidos del pensamiento débil de la posmodernidad", según cita del autor.

El teatro de las dramaturgas españolas Yolanda Pallín y Diana de Paco ocupan dos de los capítulos siguientes. El primero, introducido por un marco teórico y contextualizador que analiza la crisis de identidad en el teatro del siglo XX, se centrará en la figura de Yolanda Pallín y sus obras D.N.I, Los restos de la noche, Luna de miel, Los motivos de Anselmo fuentes, Lista negra y Trilogía de la juventud, mientras que el trabajo siguiente analiza la obra Polifonía desde el punto de vista del uso del mito para la reflexión sobre la memoria y la búsqueda de identidad femenina. A la figura de Penélope en el teatro del siglo XX se dedica otro de los estudios, en el que el autor analiza diversas obras del teatro del siglo XX con el fin de delimitar los modelos de identidad masculina y femenina que proponen los mismos a través de las figuras de la pareja odiseica: Ulises y Penélope.

El estudio de la dramaturgia de tema mitológico da paso a los dramas históricos de dramaturgas españolas contemporáneas. Partiendo de la afirmación de Buero Vallejo "el teatro histórico es valioso en la medida en que ilumina el tiempo presente", Floeck aborda el análisis tomando como punto de partida y modelo de la nueva concepción de este tipo de dramas la obra Un soñador para un pueblo del mismo autor (1957); el investigador realiza un repaso a lo largo de la evolución y la trayectoria del drama histórico en este sentido tras la muerte de Franco, se detiene en el análisis de algunas obras representativas de Concha Romero y Carmen Resino y continúa con el estudio de este campo de investigación en el capítulo siguiente, dedicado a "lo imaginario y la brujería como espacios femeninos en el drama histórico español a finales del siglo XX", para continuar con el estudio "Del drama histórico al teatro de la memoria. Lucha contra el olvido y búsqueda de identidad en el teatro español reciente", donde el autor define el teatro en el que se lleva a cabo un "proceso de rememoración del pasado reciente" característico de la segunda mitad del siglo XX, sobre todo de sus últimas décadas que ilustra con el estudio de las obras de Fernando Fernán Gómez, Las bicicletas son para el verano (1982); El álbum familiar (1982), de José Luis Alonso de Santos, y ¡Ay Carmela! (1987) y Terror y miseria en el primer franquismo, estrenada en 2002, de José Sanchis Sinisterra.

El artículo siguiente sirve de puente entre el estudio de la dramaturgia española y la portuguesa y mexicana, los tres ámbitos geográficos objeto de interés en el volumen. En él el autor acomete con éxito la arriesgada tarea de tratar una serie de rasgos y tendencias generales en el teatro actual de la Península Ibérica sin olvidar por ello la idiosincrasia y la originalidad de cada uno de los autores, pero poniendo frente a frente, a través de la figura de sus representantes más destacados, el perfil del teatro español del de finales de siglo y el del teatro portugués. Con este artículo como introducción nos adentramos, de la mano del investigador, 
en el estudio de la evolución del sistema teatral portugués a lo largo de las décadas del siglo XX, para detenernos en el trabajo dedicado a la obra de Luisa Costa Gomes, distinguida representante del teatro portugués contemporáneo.

Los dos últimos capítulos de este nutrido volumen corresponden al estudio del teatro mexicano del siglo XX, acentuando el interés por el protagonismo en sus dramas históricos de la reflexión sobre la independencia, la revolución y la Conquista en una primera etapa y, a partir de los años ochenta, el surgimiento de una nueva fase marcada por la presencia de otras tendencias como la despolitización y la reflexión metahistórica. Floeck ilustra este desarrollo a través del análisis de algunos de los dramas más representativos de esta evolución, haciendo un especial hincapié en la primera fase de este proceso evolutivo de la dramaturgia mexicana, para llegar al artículo que cierra esta enriquecedora selección de trabajos. Está dedicado al "realismo mágico y mestizaje cultural en la Trilogía Colonial de Hugo Argüelles", que comprende las obras La ronda de la hechizada (1967), La dama de la luna roja (1969) y Águila real (Isabel Moctezuma) estrenada en 1992. El análisis de cada una de ellas pone punto y final al libro que nos ocupa.

Pese a la variedad de los trabajos recogidos en el volumen y gracias a ella, el lector que a ellos se acerca recibe en su conjunto una lúcida reflexión sobre el teatro contemporáneo desde muy diversos puntos de vista. La construcción de cada uno de los estudios es sistemática: El profesor Floeck introduce siempre sus análisis en un marco teórico a través del cual aborda los aspectos más importantes con relación al tema, bien sean históricos, políticos, sociales o culturales por lo que el lector goza de una visión compleja que le facilita la comprensión de los diferentes hechos dramáticos y la reflexión sobre las razones y motivaciones de los mismos. Wilfried Floeck hace en cada una de sus aportaciones un gran esfuerzo por reflexionar desde una doble perspectiva sincrónica y diacrónica no sólo sobre el hecho teatral aislado sino el porqué, el cómo y el cuándo del mismo y busca redefinir conceptos cuya expresión en ocasiones ha sido polémica o complicada pero cuyo conocimiento resulta de vital importancia para la comprensión del fenómeno dramático y su realización actual. La organización de los capítulos de este libro, llevada a cabo por los editores, responde a una reflexión lúcida y acertada pues ofrece de forma gradual a través de sus páginas un panorama amplio del teatro contemporáneo español, portugués y mexicano, a lo que contribuye la actualidad de las investigaciones elegidas y la selección de la bibliografía que a cada una de ellas acompaña. Un libro muy recomendable para todos aquellos interesados en el teatro contemporáneo y un magnífico y merecido homenaje a esta destacada figura del hispanismo alemán.

Diana M. de Paco Serrano 